\title{
O FEMININO E O MASCULINO NA ETOLOGIA, SOCIOBIOLOGIA E PSICOLOGIA EVOLUTIVA: REVISÃO DE ALGUNS CONCEITOS
}

\author{
Conceição Maria Ramos ${ }^{1}$ \\ Marina Prieto Afonso Lencastre ${ }^{2}$
}

[Enviado a 11-11-2011. Aceite a 13-05-2013]

Resumo: O presente artigo pretende apresentar ao público leitor de psicologia alguns conceitos importantes sobre o masculino e o feminino defendidos em obras seminais da etologia humana, sociobiologia e psicologia evolutiva. As críticas clássicas das ciências sociais ao determinismo biológico não encontram eco nas actuais teorias biológicas sobre o comportamento, que enfatizam a interacção necessária entre factores genéticos, ecológicos e sócio-culturais, assim como o carácter estatístico das observações empíricas. No entanto, a conclusão do artigo aponta para o risco potencial destas disciplinas reduzirem demasiado a distância entre as causas últimas e os factores próximos de motivação, ignorando desta forma os efeitos inovadores dos processos actuais de socialização.

Palavras-chave: etologia humana, sociobiologia, psicologia evolutiva, feminino, masculino.

Feminine and masculine in ethology, sociobiology and evolutionary psychology: Review of some concepts (Abstract): This paper intends to introduce the readers of psychology to some important concepts about male and female specificities presented in seminal works of human ethology, sociobiology and evolutionary psychology. The classical critiques of social sciences on the biological determinism of these disciplines do not resonate in current biological theories about behavior. These later emphasize the interaction between genetic, ecological and socio-cultural factors, as well as the statistical nature of empirical observations. Nevertheless, the conclusion stresses the risk that these disciplines may reduce the dis-

\footnotetext{
${ }^{1}$ Mestranda da Universidade Fernando Pessoa (conceicaomariaramos@gmail.com)

2 Professora Catedrática da Faculdade de Psicologia e Ciências da Educação da Universidade do Porto e da Universidade Fernando Pessoa (mlencast@ufp.edu.pt)
} 
tance between the ultimate causes and the proximate factors of motivation, thus avoiding the innovative effects of current socialization processes.

Keywords: human ethology, sociobiology, evolutionary psychology, masculine, feminine.

O presente artigo pretende abordar alguns dos conceitos sobre o masculino e o feminino que foram desenvolvidos por autores seminais na etologia, na sociobiologia e na psicologia evolutiva. Nesse sentido, não desenvolverá as perspectivas sociais que tradicionalmente estudam estas questões a partir da história, da psicologia social ou da sociologia; é nosso intento apresentar ao leitor de psicologia três tradições de pensamento sobre os comportamentos sexuais humanos oriundas do campo da biologia evolutiva. Tendo em conta a importância crescente que estas perspectivas biológicas apresentam para o estudo de temas psicológicos relevantes, nomeadamente numa altura em que as neurociências de base evolutiva tomam uma importância evidente para a psicologia, parece-nos fundamental dar a conhecer os resultados destas disciplinas que se referem não só a comportamentos mas também a motivações para agir e a conteúdos mentais. Contrariando as críticas clássicas das ciências sociais sobre o determinismo biológico, as actuais teorias biológicas sobre o comportamento enfatizam a interacção necessária entre factores genéticos, ecológicos e sócio-culturais. Estes trabalhos acentuam a significância estatística das tendências comportamentais observadas, dando lugar a outras variantes estatisticamente menos significativas mas que, segundo a teoria evolutiva, poderão apresentar relevâncias adaptativas para um meio ambiente em mutação. O principal risco destas disciplinas consiste em reduzirem demasiado a distância entre causas últimas e factores próximos, incluindo os novos contextos da expressão comportamental e psicológica; este aspecto será abordado na conclusão.

\section{O feminino e o masculino na etologia humana}

Foi pelos fins do século XIX que o comportamento animal em meio natural começou a ganhar foro de interesse científico. No início do século seguinte, e entre outros trabalhos de importantes naturalistas da época, Oscar Heinroth (1910) concluiu que o comportamento é tão característico de uma espécie que pode ser utilizado como indicador taxonómico ao mesmo título que o são as características morfológicas. Mas foi sobretudo no seguimento dos trabalhos sobre o comportamento animal de biólogos como Konrad Lorenz, Niko Tinbergen e Karl von Frisch que a biologia do comportamento, 
nomeadamente a etologia comparativa, se apresentou como ciência através da sistematização dos seus princípios teóricos e metodológicos. O reconhecimento público destes três autores como fundadores da etologia científica com a atribuição do Prémio Nobel em 1973 - ajudou a disciplina a ganhar visibilidade pública. Uma vez mostrado que as adaptações filogenéticas afectam o comportamento de forma bastante precisa e característica nos animais, procuraram-se formas de testar a hipótese de, pelo menos em alguns dos seus aspectos, o comportamento humano poder ser igualmente afectado por processos de adaptação evolutiva.

Com efeito, depois de Darwin ${ }^{3}$, considera-se que a organização actual de qualquer sistema vivo é o resultado de uma história evolutiva de sucessivos processos de adaptação a um meio ambiente em mudança constante, através de selecção natural que opera pelo sucesso reprodutivo dos organismos adaptados e da propagação dos seus genes até às gerações seguintes. Durante a filogénese, as variações genéticas decorrentes do próprio processo de reprodução sexual, de recombinações e de mutações do material genético que impedem a sua replicação exacta, levam a que diversas variantes dos fenótipos coexistam e sejam de algum modo testadas quanto ao seu grau de adaptação ao ambiente; sobreviverão sobretudo os genótipos portadores das variantes fenotípicas adaptadas que passarão, portanto, à geração seguinte 4 . Assim, a selecção resulta no sucesso reprodutivo de alguns indivíduos e o processo adaptativo envolve as estruturas que contribuem para a sobrevivência e a capacidade em criar descendência - incluindo alguns comportamentos sociais femininos e masculinos. De facto, para Darwin, a selecção sexual consistia na escolha, operada pelos parceiros sexuais, de determinadas características morfológicas e comportamentais consideradas vantajosas do ponto de vista reprodutivo e que, a prazo, se fixariam fundando características masculinas e femininas próprias.

Um dos autores de referência na etologia humana é Irenäus Eibl-Eibesfeldt $(1989,2010)$ que, no seu livro de síntese sobre os resultados da investigação pluridisciplinar nesta área, apresenta uma panorâmica bastante abrangente da forma como esta disciplina aborda as questões do comporta-

${ }^{3}$ Recorde-se que, século e meio depois, a teoria da evolução já não é uma interpretação controversa das observações na biologia: a biologia molecular e a engenharia genética contemporâneas demonstram a homologia (origem a partir de um antepassado comum) de todos os seres vivos (Vieira, 2009). Ver esta obra também para uma apresentação da moderna "evolução do darwinismo".

${ }^{4} \mathrm{O}$ termo genótipo refere-se à composição genética do indivíduo; fenótipo designa a totalidade das características aparentes do indivíduo, resultantes da interacção entre o genótipo e o ambiente. 
mento humano. Será nesta obra que nos iremos centrar para abordar as diferenças entre o feminino e o masculino do ponto de vista da etologia humana.

Situando o nascimento da sua disciplina em meados da década de 60, em plena controvérsia entre perspectivas comportamentalistas e culturalistas, Eibl-Eibesfeldt (EE) propõe-se ultrapassar este dualismo e dar voz a um realismo crítico (Lorenz, 1973; Popper, 2010) que sugere que parte importante do comportamento humano está enraizado biologicamente. Nesse sentido, e procurando discernir numa grande pluralidade de culturas humanas as tendências universais próprias à espécie e a sua possível história evolutiva, recorre a uma abordagem comparativa entre culturas e entre o comportamento humano e animal. Procura estudar essas tendências universais através da análise das homologias (semelhanças observáveis devidas à herança de um antepassado comum) e das analogias comportamentais (semelhanças devidas à adaptação a ambientes similares). A sua atenção é dirigida pela necessidade de considerar as funções desempenhadas pelos diversos comportamentos observados, de modo a reconstruir as possíveis pressões selectivas que lhes deram forma e os justificam. Trata-se de destacar o que no comportamento actualmente observável pode ser compreendido como resultado de uma adaptação filogenética e, nesse sentido, relacionado com aspectos inatos, sem esquecer que a aprendizagem se faz num quadro culturalmente determinado que está sempre presente e em interacção com o biológico. Aliás, o autor mostra que a própria evolução cultural é um poderoso mecanismo de adaptação ao meio ambiente e pode suscitar alterações genéticas por selecção fenotípica. O caso da tolerância à lactose é exemplar: foi apenas depois da descoberta da agricultura e da pastorícia que os adultos começaram a beber leite e que a alteração genética - a produção da enzima digestiva correspondente - foi seleccionada (Cavalli-Sforza, 1981)5. Será, pois, necessário atender aos diversos aspectos biológicos e culturais e à sua interacção para poder dar conta da complexidade criativamente adaptativa do comportamento humano,

No que à diferença entre homens e mulheres diz respeito, EE distingue as diferenças específicas que se referem a características que apenas se encontram em um dos sexos, e as diferenças típicas que, embora comuns, se costumam apresentar de modo diferenciado segundo o sexo. O seu ponto de partida é a observação de que estas diferenças, e mesmo a sua acentuação, são uma preocupação comum a todas as culturas humanas conhecidas, ainda que de modos e em graus diversos. No que diz respeito à aparência do corpo, por exemplo, a acentuação dos ombros nos homens e das ancas nas mulheres através do vestuário ou adornos variados, parece corresponder a formas esquemáticas reconhecidas como femininas ou masculinas por crianças

\footnotetext{
5 Esta referência e os trabalhos citados a seguir são retirados do livro de EE.
} 
púberes, em culturas tão diferentes como a alemã ou a tanzaniana (Jessen, 1981). Assim, a característica mais frequentemente observada para o masculino, o triângulo apoiado no ápice, traduziria a ênfase dos ombros na silhueta dos homens e poderia ser interpretada como a sobrevivência de um mecanismo de reconhecimento sexual inato, correspondendo a uma antiga característica anatómica hoje perdida: a existência de tufos de pelo que, de facto, alargavam essa zona do corpo e é atestada pelos padrões de distribuição pilosa actuais (Leyhausen, 1983).

No que diz respeito aos papéis de género - o comportamento esperado e prescrito culturalmente para homens e mulheres (EE, 2010) - a divisão do trabalho entre os indivíduos dos dois sexos parece ser a norma, fundamentada nas diferenças anatómicas e na fisiologia reprodutiva: são as mulheres que engravidam e amamentam os filhos, permanecendo condicionadas durante longos períodos de tempo pelos cuidados a prestar às crianças. São também elas quem geralmente se ocupa da manutenção dos locais de habitação e das necessidades alimentares do grupo no que diz respeito à recolecção ou a trabalhos hortícolas perto dos locais de habitação (EE, 2010). Por outro lado, o esqueleto forte e alongado, a composição específica das fibras musculares, as características do metabolismo basal e a maior capacidade de oxigenação do organismo, permitirão aos homens apresentar uma maior facilidade nas actividades que requerem força e rapidez. (EE, 2010): são eles que se ocupam da caça de animais e das actividades relacionadas com a defesa do território. $\mathrm{O}$ facto de este ser o padrão geral encontrado nas actuais sociedades de caçadores-recolectores estudadas, dos bosquímanos !Kung do Calahari (Shostak, 1982) aos Esquimós (Lee \& DeVore, 1968), leva a pensar que os antigos grupos pré-históricos, com recursos de algum modo semelhantes, provavelmente também tenham adoptado comportamentos e formas de organização social semelhantes.

A hipótese etológica defende, pois, que parte das diferenças significativas entre homens e mulheres foi sendo construída ao longo da evolução do ser humano como espécie e se baseia em grande parte no facto de este necessitar de cuidados maternos prolongados. Teria havido uma diferenciação progressiva a partir das características anatómico-fisiológicas básicas próprias a cada sexo e as funções primariamente designadas por elas, ao nível comportamental mas também ao nível da morfologia do corpo e do próprio uso do cérebro. São disto exemplo a acentuação do dimorfismo sexual humano no que diz respeito à largura das ancas, assim como a menor especialização hemisférica do cérebro feminino (Levy, 1972). Este estaria relacionado com maiores capacidades verbais e uma utilização mais acentuada da linguagem como forma de comunicação social, nas mulheres. Assim sendo, enquanto as mulheres ficariam ocupadas durante longos períodos de tempo pela gravidez, amamentação e outros cuidados a prestar às crias, os 
homens teriam organizado expedições em busca de alimento, nomeadamente através da caça, organizando e defendendo o território-base onde aquelas permaneceriam. Ter-se-á assim reforçado uma divisão de trabalho adaptada à sobrevivência dos pequenos grupos de caçadores-recolectores que até muito recentemente povoaram a terra. De facto, o início da agricultura e a domesticação de animais terá acontecido somente há cerca de 10.000 anos. O longo passado evolutivo que as precedeu contribuiu para estabelecer diferenças comportamentais importantes entre homens e mulheres, e estas terão sido reforçadas culturalmente em certas tradições ${ }^{6}$.

A "unidade fisiológica" mãe-filho, nas palavras de EE (2010), baseia-se em mecanismos etológicos como a cunhagem (imprinting). A cunhagem é um mecanismo de memorização precoce e irreversível que estabelece o comportamento de seguir em alguns animais que andam logo após o nascimento e que, em certas espécies, determinará mais tarde o comportamento sexual (Lorenz, 1935). A cunhagem apoia-se em poderosos mecanismos hormonais que fazem dela um factor muito antigo na diferenciação filogenética dos mamíferos. Por exemplo, a oxitocina é uma hormona produzida pela mãe durante e após o parto e que desencadeia as contracções do útero e a segregação de leite. É também uma hormona segregada durante os encontros amorosos adultos. É, portanto, considerada uma hormona vinculativa (Klopfer, 1971; Keverne, Levy, Poindron, \& Linssay, 1983).

Também nos humanos, embora sob formas modificadas, a unidade mãe-filho foi determinante para o desenvolvimento das diferenças comportamentais entre os sexos. A evolução de um período alargado de cuidados parentais foi tornada necessária para a protecção de uma cria imatura: as sinalizações e repostas mútuas entre crias e adultos, características da vinculação entre mãe e bebé, parecem ser um requisito para a elaboração das formas altamente elaboradas e diferenciadas da sociabilidade humana. Com efeito, trata-se de um primeiro modo de relação entre indivíduos, precursor da formação de laços amigáveis e individualizados entre adultos e essencial para a constituição de grupos cooperativos capazes de manter a unidade, a despeito das questões da ambivalência - procura e evitamento de contacto com o outro - e da agressividade. A vinculação humana permite assim as relações de proximidade para além do que parece ser a unidade social natural própria aos animais parentais monogâmicos, isto é, o casal parental e o seu filho.

\footnotetext{
${ }^{6}$ As sociedades pós-industriais contemporâneas modificaram substancialmente as condições adaptativas anteriores e actualmente encontramo-nos face a uma importante reconfiguração entre sexualidade e papéis de género, à qual a discussão entre as ciências biológicas e sociais não é alheia. Esta discussão não constitui, no entanto, o foco do nosso trabalho.
} 
Significa isto que, apesar de se tratar de uma evolução mais recente, a neotenia do bebé humano terá encorajado a participação paterna de modo a corresponder às necessidades da criança e à protecção da própria mãe. $\mathrm{O}$ conceito de neotenia refere-se à retenção de características juvenis no adulto, e ao facto de os humanos, em comparação com outros primatas, nascerem muito imaturos e incapazes de sobreviverem sozinhos. Apresentam um desenvolvimento lento e conservam capacidades generalistas ao longo da vida, mantendo portanto uma grande adaptabilidade às mudanças externas. As dificuldades de uma longa gravidez, de um parto complicado pelo tamanho da cabeça do nascituro, juntamente com a imaturidade acentuada e prolongada da criança, terão sido factores especialmente fragilizantes para a mãe humana. De facto, parece não haver sociedades humanas conhecidas que não constituam casais ou relações familiares estáveis em torno da mãe (EE, 2010). O pai é, nas culturas referenciadas por EE, uma figura de referência e de vinculação. Tende a estabelecer com a criança modos de relação em que os jogos fisicamente estimulantes são mais frequentes e contribui, tal como a mãe, para a diferenciação sexual, na medida em que interage de modo diferenciado de acordo com o facto de a criança ser rapaz ou rapariga; aliás, logo por volta dos dois anos de idade, os rapazes mostram preferência pelo pai como companheiro de jogos, enquanto as raparigas preferem a mãe (Lamb, 1977). O alargamento do período juvenil em contacto estreito com os progenitores abre a novas possibilidades de aprendizagem comportamental complexa, nomeadamente através da brincadeira, da utilização de formas rituais de vinculação e de agressão-divertimento, ou da imitação verbal e comportamental de modelos adultos que têm como efeito facilitar a integração na vida cooperativa do grupo

Pese embora as variações culturais nas várias sociedades observadas, em geral os homens ocupam posições hierarquicamente elevadas, por exemplo como porta voz e representantes da colectividade incluindo, de forma não exclusiva, a mediação com o transcendente nos rituais religiosos. Tais actividades adquiriram um valor social acrescido e de liderança, mesmo nas sociedades em que é a linha de filiação materna que prevalece (EE, 2010). Esta dominância dos homens, tida pelo autor como herança primata, parece ser influenciada pelos níveis hormonais: a testosterona tem efeitos androgénicos na formação da massa muscular e, portanto, no tamanho e aparência do corpo. Afecta os níveis de agressividade masculina incluindo a preparação para a acção, e a sua quantidade varia com o grau de dominância no grupo. Há, aliás, observações que parecem apontar para a existência, nos homens, de uma apetência pelo sucesso e pelos comportamentos consumatórios induzida pelos androgénios, cujo nível varia em função daqueles (Mazur \& Lamb, 1980). Para os autores, não é claro se os níveis de androgénios constituem um factor causal da dominância ou se simplesmente co-variam com o 
estatuto. A agressividade masculina parece depender da exposição androgénica associada a contextos sócio-culturais em que pode haver contestação do estatuto.

Diferenças específicas a cada um dos sexos são também visíveis nos comportamentos sexuais actuais, incluindo no que diz respeito a formas de aproximação e de namoro. Com efeito, os estímulos especificamente sexuais são diferentes para cada sexo. Alguns parecem agir de forma pouco consciente como, por exemplo, os estímulos olfactivos relacionados com estados hormonais do corpo. Outros, como os estímulos visuais, têm um valor culturalmente modelado, apesar da pré-orientação dos padrões perceptivos no que diz respeito a silhuetas típicas e a caracteres sexuais secundários. A sexualidade humana, embora apresentando características próprias, parece ter sido marcada pela herança de dois padrões biológicos típicos de diferentes períodos da evolução filogenética: o primeiro, próprio a uma sexualidade "agonística", é marcado pela dominância masculina e pela submissão feminina; o segundo, que aparece com os animais parentais como os mamíferos, é próprio a uma sexualidade afiliativa e é propiciador de relações individualizadas que, de algum modo, controlam o primeiro (EE, 2010). Segundo o autor, a par desta herança, a sexualidade humana apresenta características próprias como a ovulação invisível ou o coito escondido, que terão contribuído para a criação de laços afectivos fortes e prolongados entre os humanos, assim como para a exclusividade do casal.

Em geral, o processo de formação do casal humano estaria marcado pelas diferenças entre homens e mulheres, embora possa ser socialmente codificado de diferentes modos em diferentes culturas, quer no que diz respeito às formas de auto-apresentação, quer às formas de estabelecimento de contacto. É o homem quem tende a tomar a iniciativa e a mulher a seleccionar o parceiro, opondo alguma resistência inicial ao homem. EE (2010) fala de uma "exibição de corte" caracteristicamente masculina que consiste numa "projecção positiva do self" (esta última, aliás, também verificável no outro sexo) que não visaria mostrar uma posição dominante perante a parceira, mas sim perante terceiros e deste modo demonstrar a sua capacidade de protecção e cuidado. Numa fase posterior entrariam em jogo comportamentos próximos do comportamento infantil de apelo à vinculação, juntamente com todo um conjunto de movimentos expressivos e de interacções que fazem parte do repertório afiliativo inato, como o contacto visual, o sorriso, o arquear das sobrancelhas e a sincronização dos movimentos.

A antiga associação entre sexualidade masculina e dominância e entre sexualidade feminina e submissão poderia, pelo menos em parte, explicar algumas das patologias do comportamento sexual como regressões a formas de sexualidade mais antigas em termos filogenéticas, um tipo de sexualidade agonística com hipertrofia de alguns componentes da sexualidade normal. 
Seriam disto exemplo algumas formas patológicas de exibicionismo masculino (Müsch, 1976) ou um certo tipo de homossexualidade masculina caracterizada pela expressão brutal da dominância e pela mudança frequente de parceiro. Por outro lado, é a actualização ontogénica da herança filogenética que permite que o comportamento sexual, como aliás qualquer comportamento, seja modelado por factores do ambiente social, eventualmente num sentido desviante à norma. Assim, alguns casos de escolha de objecto homossexual são explicados por um processo próximo da cunhagem (imprinting), no sentido da fixação de determinadas características do parceiro escolhido ou pela marca de uma associação com experiências sexuais mais ou menos precoces (von Krafft-Ebing, 1924; Leonhard, 1966). Estes casos relacionar-se-iam frequentemente com episódios de sedução juvenil. Outros casos, ainda, seriam explicados por factores hormonais precoces, nomeadamente pré-natais (Dörner, 1980; Gladue, Green, \& Hellman, 1984), sendo que a hipótese da existência de uma predisposição genética é reforçada pelas conclusões de estudos de pares de gémeos monozigóticos (Kallmann, 1952). EE (2010) afirma, ainda, existirem culturas para as quais não existem homossexuais. A afirmação refere-se a pessoas homossexuais e não a comportamentos ou actos homossexuais, o que faz recordar o facto de que só a partir do séc XIX se considera existir algo como uma identidade marcada, se não definida, pela escolha de objecto sexual.

Um número importante de observações, quer em condições laboratoriais quer em investigações interculturais, parece mostrar que logo a partir do nascimento as raparigas tendem a ser mais calmas do que os rapazes, sorrindo mais, o que virá a desenvolver-se como um maior interesse pela comunicação com o outro (Feldman, Brody, \& Miller, 1980; Phillips \& Dubois, 1978). Cedo mostrarão mais comportamentos altruístas (Shigetomi, Hartmann, \& Gelfand, 1981), melhores competências verbais e mais obediência às sugestões dos adultos (Witkin, Goodenough, \& Karp, 1967). Os rapazes evidenciam precocemente mais apetência para a actividade física (Block, 1976), mais agressividade (MacCoby, 1980) e mais independência, por exemplo distanciando-se mais das mães na exploração do ambiente circundante (Ley \& Koepke, 1982). Os rapazes apresentam também melhor orientação espacial (Witkin, Goodenough, \& Karp, 1967), menos ambivalência em relação ao contacto com estranhos (MacCoby \& Jacklin, 1974) e comportamentos de exibição mais frequentes (Hold, 1974, 1976, 1977).

Em idade pré-escolar, ambos os sexos mostram preferência por companheiros de jogo do mesmo sexo, o que estaria ligado aos interesses diferenciados de ambos os grupos revelados, por exemplo, na diferença de temas de desenho livre (Sbrzerny, 1976). E, a despeito do novo interesse pelo sexo oposto, muitas destas diferenças ganham nova dimensão a partir da puberdade (Degenhardt \& Trautuer, 1979): para as raparigas, mais habilidades ver- 
bais, velocidade e acuidade perceptiva e, para os rapazes, mais habilidades quantitativas e de orientação espacial; para as raparigas, mais conformidade social, orientação para as pessoas e interesses sociais, para os rapazes mais auto-confiança, mais orientação ocupacional e interesses materiais; para as raparigas uma auto-imagem relacionada com a interacção com os outros, para os rapazes uma auto-imagem baseada nas suas competências assertivas.

Parte destas diferenças poderão ser explicadas pela aprendizagem: o reforço positivo mais ou menos intencional do comportamento esperado e prescrito culturalmente é bastante precoce (Fagot, 1978; Goldberg \& Lewis, 1969) sendo que, pelo menos parcialmente, modos diferentes de relação com a criança corresponderão a comportamentos também eles diferenciados (Block, 1976; Fagot, 1978; Keller,1979; Tauber, 1979). Há também imitação de modelos do mesmo sexo, possivelmente pela predisposição inata da criança para o fazer, assim como identificação potenciada pela força dos laços afectivos (Grusec \& Brinker, 1972; Slaby \& Frey, 1975; Trautner, 1979). Mas uma vez conseguida a categorização do sexo de pertença pela criança, as influências externas perdem parte da sua influência, essencialmente pela necessidade de manter a consistência cognitiva (Kohlberg, 1966; Trautner, 1979). No entanto, a designação social do sexo da criança e a educação correspondente não determinam, só por si, a identidade sexual. Observações de casos em que houve castração acidental e tratamento hormonal subsequente no sentido da feminização (Durden-Smith \& Desimone, 1983; Money \& Ehrhardt, 1972), ou casos de deficiência genética no processo normal de masculinização anatómica do bebé, mostram que as características cromossómicas e hormonais masculinas não podem ser apagadas pela educação no sentido de uma identidade feminina bem estabelecida (Imperato-McGinley, Peterson, Gautier, \& Sturla, 1979; Rubin, Reinich, \& Haskett, 1981). Por outro lado, o estudo do que aconteceu em meados do século passado em kibbutz israelitas (Spiro, 1979; Tiger \& Shepher, 1975) mostra as dificuldades de um programa fortemente constrangido ideologicamente no sentido de um igualitarismo compreendido como abolição de qualquer diferença - também entre papéis de género. A institucionalização de práticas como a educação precoce das crianças por instituições comunitárias empenhadas no cumprimento deste objectivo, a limitação das relações de afecto individualizadas nomeadamente no que diz respeito à ligação da mãe com o bebé, a distribuição do trabalho indiscriminadamente pelos dois sexos ou a preocupação em equalizar a aparência do corpo, acabaram por não resultar quer no sentido de terem promovido um sentimento de desadequação nomeadamente nas mulheres e em particular nas mães - quer no sentido de não terem efectivamente apagado a diferença de interesses e modos de comportamento diferenciados sexualmente nas crianças assim educadas. Estaremos, pois, confrontados com as limitações que a biologia impõe às tentativas 
de abolição das diferenças mas não, acentua $\mathrm{EE}$, à sua valorização como igualmente valiosas para o futuro da nossa espécie.

$\mathrm{O}$ facto de a ciência etológica procurar compreender o comportamento humano actual como testemunho de um processo adaptativo lento e desenrolado ao longo da maior parte da nossa história evolutiva, pode ajudar a formular interrogações relativas à adequação dos papéis de género tradicionais - tributários de determinadas condições sócio-ambientais - à sociedade pós-industrial actual. De modo mais genérico, interroga a capacidade humana em harmonizar os rápidos ritmos da evolução cultural com os da evolução biológica, muitíssimo mais lentos. Em todo o caso, a tónica é posta na necessidade de reconhecer a herança biológica para melhor a integrar, alertando para os problemas que o seu desconhecimento ou negação podem acarretar, mais não seja por ineficiência. EE não deixa de acentuar a liberdade de escolha que a própria combinação de padrões de comportamento de diferentes sistemas funcionais proporciona, acentuando também as questões relativas ao controlo voluntário da acção ou à habilidade em separar comportamentos e emoções. Com efeito, a evolução do cérebro humano, nomeadamente a corticalização e a lateralização, com destaque para a capacidade de linguagem, abriu novas possibilidades de reflexão e de autoconsciência, libertando numa parte importante os padrões comportamentais dos rígidos mecanismos desencadeadores mais antigos.

A perspectiva evolutiva sobre os comportamentos animais e humanos desenvolvida pela etologia foi integrada pela sociobiologia, a par da genética e da ecologia do comportamento. Esta disciplina tende a ser mais formalista do que a etologia, nomeadamente pela aplicação de modelos preditivos do funcionamento social.

\section{O feminino e o masculino na sociobiologia}

A obra de Edward Osborn Wilson, Sociobiology, The New Synthesis (1975), expôs e desenvolveu conceitos da biologia evolutiva, propondo novas perspectivas sobre os comportamentos sociais animais e suscitando controvérsias, nomeadamente no último capítulo "Man: from Sociobiology to Sociology", em que defendeu que os mesmos princípios explicativos podem ser aplicados ao comportamento humano. Procurando integrar observações vindas de várias áreas científicas, nomeadamente da etologia, ecologia e genética das populações e utilizando modelos matemáticos complexos com intuitos explicativos e preditivos, a sociobiologia encara o comportamento social como sendo explicável geneticamente, numa perspectiva de análise de custos e benefícios. 
Com efeito, segundo esta abordagem, o critério de sucesso de uma determinada adaptação individual, ou seja, a sua vantagem evolutiva, é o da sobrevivência dos genes que codificam essa adaptação. Tudo o que reduza ou dificulte o sucesso genético será considerado como um custo - por exemplo, o risco envolvendo a reprodução, o tempo e o trabalho nela investidos. $\mathrm{O}$ benefício será medido pelo sucesso na passagem dos genes à geração seguinte e implicará um saldo positivo perante o peso do custo. Com a tónica posta no gene - e não no organismo - como unidade de selecção, um comportamento será adaptativo se maximizar as hipóteses de sucesso reprodutivo, medido em função das taxas de sobrevivência e de reprodução dos genes do indivíduo em causa. Considera-se, portanto, que alguns comportamentos são, pelo menos em parte, directamente influenciados por determinados genes ou combinações particulares de genes. Recorde-se que, na teoria clássica, a selecção natural se exerce via fenótipo e não directamente sobre o genótipo, uma vez que é aquele que interage com o ambiente

A sociobiologia vai alargar o conceito do sucesso adaptativo do indivíduo ao seu grupo de parentes. A teoria da "vantagem inclusiva" (Hamilton, 1964) defende que a selecção favorece também os genes dos organismos geneticamente aparentados, ou seja, que partilham parte do património genético com o indivíduo. Deste modo, um comportamento "altruísta", no sentido em que favorece um parente em desfavor de si-próprio, acabará por representar um egoísmo genético na medida em que, finalmente, resulta na passagem dos genes do próprio indivíduo às gerações seguintes. Daí a metáfora do "gene egoísta" de Dawkins (1976).

Nesta perspectiva, a persistência de comportamentos não reprodutivos como a homossexualidade poderia ser explicada, apesar da sua aparente contradição evolutiva. Segundo Wilson (2004), há uma forte possibilidade de que comportamentos homossexuais tragam benefícios específicos, favorecendo eventualmente a transmissão genética de alguns impulsos altruístas. Indivíduos homossexuais poderiam ter sido um elemento importante na primitiva organização social humana, eventualmente ocupando posições vantajosas para ajudar os seus parentes. Se estes fossem assim beneficiados em termos de rácios de sobrevivência e de reprodução, os genes comuns seriam transmitidos às gerações seguintes incluindo, ainda que não directamente, os que predispõem os indivíduos à homossexualidade. A hipótese necessita pois da confirmação de que, pelo menos em parte, a predisposição à homossexualidade é herdada, como sugerem alguns estudos de gémeos. A sua expressão seria, no entanto, dependente do ambiente familiar e das experiências infantis.

Também o comportamento materno pode ser visto, nesta perspectiva, como um comportamento adaptado cuja selecção se justifica porque, a despeito do investimento que exige, aumenta a probabilidade de sobrevivência 
dos filhos e a sua reprodução e, portanto, a passagem dos genes maternos às gerações seguintes. A teoria do investimento parental (Trivers, 1972), definido como aumentando as possibilidades de sobrevivência de uma cria em detrimento da capacidade do progenitor em investir quer na sua própria sobrevivência quer na sua capacidade reprodutiva - noutras crias, portanto procura mostrar como os pais estão dispostos a investir nos seus filhos - e não nos dos outros - na medida em que estes, por sua vez, se reproduzem. A teoria do investimento parental sugeriu diversos desenvolvimentos como, por exemplo, a hipótese de um conflito genético entre pais e filhos (Trivers, 1974), explicado pela diferença de interesses entre eles: para os primeiros, é mais favorável dividir equitativamente os seus cuidados por todos os filhos enquanto que cada um dos segundos procura maximizar o investimento parental para si próprio, rivalizando com os irmãos.

Particularmente interessante para este artigo é, contudo, a teoria da selecção sexual proposta pela sociobiologia. Como vimos acima, Darwin (1871) tinha considerado que a escolha de um parceiro sexual impõe uma selecção dos indivíduos do sexo oposto e, nesse sentido, apresentou a questão da escolha pelas fêmeas e da competição entre os machos como essencial para este processo. A sociobiologia vai procurar construir modelos preditivos que permitam fundamentar e desenvolver esta hipótese: no que diz respeito a alguns animais, nomeadamente os mamíferos, são as diferenças na própria fisiologia reprodutiva entre machos e fêmeas que explicam a diferença nos seus comportamentos, com o menor potencial reprodutivo das fêmeas a determinar o seu maior interesse pelo bom cuidado dos seus filhos. Por outro lado, e acrescendo ao facto de a gravidez e parto lhes acarretarem riscos específicos, as fêmeas serão mais selectivas na escolha do um parceiro que ofereça garantias de investimento, enquanto os machos tenderão a procurar uma maior variedade de fêmeas que possam fecundar ${ }^{7}$. O tipo de casal parental formado dependerá - para além de outros factores internos à estruturação do grupo - das condições ecológicas: num ambiente pobre em recursos, por exemplo, a monogamia favoreceria a prestação de cuidados conjuntos por ambos os pais e a respectiva divisão de tarefas, de modo a aumentar as possibilidades de sobrevivência das crias.

É neste contexto que surgirão um conjunto de trabalhos procurando compreender a evolução da escolha do parceiro sexual e os modos como esta se processa, nomeadamente por parte das fêmeas (Kokko, Brooks, Jennions, \& Morley, 2002). As questões vão desde tentar compreender porque razão

\footnotetext{
${ }^{7}$ A hipótese de Trivers (1972) prediz que o sexo que investe mais nas crias (geralmente, mas não sempre, o feminino) será mais selectivo na escolha de parceiro, enquanto o que investe menos (o masculino) será mais competitivo com os membros do seu próprio sexo na luta pelo acesso ao primeiro.
} 
determinados machos terão mais probabilidades de sucesso do que outros, a calcular os custos, advindos da selectividade das fêmeas, para a sua fecundidade. Considera-se a selecção directa de características masculinas como a saúde e a fertilidade, a capacidade de proporcionar melhores recursos e a oferta de cuidados às crias, e considera-se a selecção indirecta de traços que lhes estão associados e que virão a ser considerados atractivos pelas fêmeas como, por exemplo, o tamanho e o brilho das penas nas aves, ou o tamanho e a simetria do corpo nos mamíferos. Consideram-se também as vantagens directas da selecção sexual para as fêmeas, por exemplo em termos de fecundidade acrescida, ou as vantagens indirectas, como no que diz respeito ao sucesso reprodutivo das suas crias.

Deste modo, para além de prever que os indivíduos apresentarão os comportamentos que se revelaram vantajosos do ponto de vista evolutivo, é o número de genes passados às gerações seguintes que a sociobiologia considera. Por efeito da selecção exercida sobre eles, determinada população no seu conjunto acabará por apresentar "estratégias evolutivamente estáveis"8 (Maynard Smith \& Price, 1973) que se sobreporão a quaisquer outras alternativas, mantendo em equilíbrio populacional uma proporção particular de características comportamentais. A existência destas estratégias é, portanto, uma hipótese preditiva da frequência de determinados genes numa população, confirmada pela correlação entre a frequência dos genes predita e os genes efectivamente expressos ${ }^{9}$.

É um facto que esta disciplina, com os seus modelos matemáticos, tem permitido fazer previsões sobre os comportamentos sociais animais em determinadas situações definidas dentro da lógica dos factores genéticos (nomeadamente o grau de parentesco) e dos factores ecológicos, com destaque para o grau de acessibilidade ou de dificuldade de acesso a recursos. No entanto, a aplicação da sociobiologia às sociedades humanas revela-se muito problemática, pela grande variedade e complexidade dos factores envolvidos. Esta foi a razão que levou a que a sociobiologia humana fosse duramente criticada, não só a partir das ciências sociais (Sahlins, 1977) como no seio da própria história da biologia evolutiva (Tort, 1985). Estes trabalhos criticaram tanto os aspectos conceptuais e metodológicas reducionistas como os riscos da sua aplicação social e política.

${ }^{8} \mathrm{O}$ conceito é frequentemente criticado como finalista por veicular a ideia de uma intenção consciente, à semelhança do conceito de equilíbrio de John Nash na teoria dos jogos que, esse sim, pressupõe a habilidade e racionalidade dos jogadores, bem como o seu conhecimento do jogo. Foi sugerido o termo "estado evolutivamente estável" como mais apropriado (Eibl-Eibesfeldt, 2010).

${ }^{9}$ Esta metodologia tem sido criticada pela sua circularidade, na medida em que tal correlação pode ser devida à utilização indirecta da mesma medida para a frequência de genes e para a definição da estratégia. 
Há, apesar de tudo, trabalhos de bioantropologia que, sem ignorarem as questões inerentes a esta última disciplina, procuram traçar uma " história natural da monogamia, do adultério e do divórcio" (Fisher, 1994) baseando-se em grande parte na sociobiologia. Apresentando dados etnográficos e estatísticos sobre o casamento, as suas variantes e as suas vicissitudes, a autora desenvolveu hipóteses sobre, por exemplo, a relação entre um aparente pico de divórcios após quatro anos de relação e o período de maior dependência infantil, ou a correlação entre a independência económica das mulheres e as taxas de divórcio.

Outros desenvolvimentos tentam ir mais longe. Para além de considerarem que, nos humanos, as diferenças comportamentais inatas entre bebés do sexo feminino e masculino desencadeiam comportamentos diferenciados nos pais, alguns autores desenvolveram a "hipótese Trivers-Willard" (1973) segundo a qual as fêmeas de menor estatuto social - e portanto com acesso a recursos mais limitados - tendem a ter mais filhos do sexo feminino do que as de estatuto superior, sendo o factor ecológico combinado com outros factores biológicos. Valerie Grant (1998) relaciona o acréscimo de filhos do sexo masculino nas mulheres hierarquicamente dominantes com a variação dos níveis maternos de testosterona, expondo a hipótese de um ajustamento entre a fisiologia feminina e o seu estatuto social que teria consequências, quer ao nível do sexo dos filhos, quer ao nível do seu estilo de maternagem: estas mulheres teriam níveis mais elevados de testosterona que fariam delas mulheres mais activas, assertivas e independentes do que as outras mulheres. A forma como tratam os filhos seria também diferente, sendo que os rapazes criados por elas teriam mais vantagens competitivas sobre os outros, em contraste com as raparigas que teriam mais vantagem em ser educadas no estilo que as mulheres subdominantes tendem a usar.

A sociobiologia procura, pois, estabelecer modelos prováveis de mudança evolutiva, testando aspectos particulares em casos particulares, centrando as suas explicações nas "causas últimas" dos comportamentos no sentido de Tinbergen (1951), ou seja, na sua função adaptativa e no seu possível processo evolutivo. Não nega por isso que o comportamento individual esteja também dependente das condições actuais de desenvolvimento do organismo, nomeadamente no que aos seres humanos diz respeito, dadas as suas particularidades mentais e as do meio cultural em que se inserem. É com base nestas ideias da sociobiologia que a mente humana vai estar em estudo com a psicologia evolutiva.

\section{O feminino e o masculino na psicologia evolutiva}

Com a psicologia evolutiva trata-se, então, de oferecer o ponto de vista da "mente adaptada" (Barkow, Cosmides, \& Tooby, 1992), isto é, de 
explicar o funcionamento mental como um conjunto de adaptações aos problemas de sobrevivência e de reprodução enfrentados pelos humanos no decurso da sua evolução. O livro de D. Buss Evolutionary Psychology (1999) permanece uma obra síntese de referência e é sobretudo nele, e nos trabalhos aí citados, que nos iremos basear.

A psicologia evolutiva procura investigar algumas hipóteses derivadas da teoria sociobiológica, aplicando os modelos heurísticos da psicologia cognitiva ao estudo da mente identificada como o produto do funcionamento cerebral. Mais exactamente, vai utilizar um modelo de compreensão do funcionamento mental baseado na metáfora computacional em que a mente é vista como um dispositivo processador de informação: o input é constituído por formas de informação específicas que, depois de transformadas através de regras de decisão, gerarão determinados comportamentos como output. A neurobiologia cerebral representará o hardware, mas é o software, os programas transformadores da informação, que estão aqui em estudo.

Nesse sentido, a psicologia evolutiva propõe um modelo modular da mente que essencialmente integra módulos especializados, ou "domínio-específicos", no tratamento de informação psicológica particular. A existência de apenas um dispositivo de processamento generalista implicaria considerar um tal número de opções combinadas - uma "explosão combinatória" - que rapidamente se tornaria ineficaz na resolução de problemas psicológicos concretos. Estes módulos têm, no entanto, graus de especificidade variável, sendo alguns deles mais "domínio-generalistas", nomeadamente os dedicados à cognição ou ao tratamento das emoções (Tooby \& Cosmides, 1992). A ideia da mente como software modular significa também que a psicologia evolutiva considera necessária a adopção de uma perspectiva funcionalista, na medida em que só a compreensão da especificidade da função de determinado módulo na resolução de um dado problema adaptativo abrirá caminho à compreensão do seu modo de funcionamento.

Um exemplo interessante para o nosso tema é o modo como a psicologia evolutiva analisa a tendência para competências espaciais diferenciadas entre homens e mulheres: a especificidade masculina manifesta-se numa maior facilidade em rodar figuras mentalmente, ler mapas ou orientar-se num labirinto, enquanto as mulheres ultrapassam os homens nas tarefas espaciais que implicam a memória de objectos e a sua localização (Silvermane \& Phillips, 1998). Esta diferença é interpretada como reflectindo a adaptação à divisão de trabalho própria dos grupos pré-históricos: as características masculinas seriam particularmente adaptadas à caça (Tooby \& DeVore, 1987), as femininas à recolecção de plantas. As questões relacionadas com o estudo do raciocínio espacial seriam, portanto, "domínio-específicas" quando perspectivadas a partir dos problemas espaciais adaptativos que homens e mulheres enfrentaram no decorrer da história evolutiva. 
A ideia fundamental é que a mente humana se confronta essencialmente com a resolução de dois tipos de problemas universais - o problema da sobrevivência e o problema da reprodução. Possui dispositivos dedicados à sua resolução que correspondem a uma série de "mecanismos psicológicos evoluídos" (Buss, 1999). Estes são conjuntos de processos que, à semelhança do olho que é informado pela luz e não pelo som, utilizam um determinado tipo de informação, transformando-a através de regras de decisão do tipo "se...então". Estas regras são, de algum modo, derivadas de regularidades estatísticas encontradas no meio ambiente. Trata-se de soluções que foram seleccionadas porque estão adaptadas à resolução dos problemas que a espécie humana enfrentou no "ambiente de adaptação evolutiva", há cerca de 150.000 anos. Poderão ser de tipo fisiológico, psicológico ou comportamental e não são necessariamente adaptadas às condições de vida actuais. A flexibilidade do comportamento humano é, neste quadro, explicada pela especificidade, complexidade e número destes mecanismos.

No que diz respeito aos problemas relacionados com a reprodução humana, grande parte dos trabalhos no âmbito da psicologia evolutiva ocupam-se de problemas tais como compreender como homens e mulheres tendem a seleccionar o seu parceiro dentro de estratégias de longo ou curto prazo, sendo que as hipóteses agora em apreço são especificamente psicológicas. Desenvolvendo o quadro das teorias sociobiológicas do investimento parental e da selecção sexual, uma das hipóteses consideradas é de que a escolha selectiva de um parceiro, exercida continuadamente por parte das mulheres ao longo de centenas de milhares de anos de evolução, desembocou numa preferência feminina por homens que apresentem características de maior valor adaptativo para elas e para os seus filhos. As que não desenvolveram preferências adaptativas relevantes no contexto evolutivo acabaram por ter sido eliminadas do processo pelo seu insucesso reprodutivo; as que vivem actualmente continuam a carregar os genes para estas preferências, herdados das suas antepassadas (Buss, 1999).

Trata-se aqui de "mecanismos psicológicos evoluídos" complexos, na medida em que implicam a avaliação de condições futuras a partir de sinais actuais não unívocos que devem, de algum modo, ser correctamente pesados, interpretados e integrados. Envolvem preferências diferentes por diferentes aspectos tendentes a resolver problemas adaptativos, também eles diferenciados (Buss, 1999). É o facto de serem especificamente dirigidos à resolução de problemas específicos que permite uma resolução eficaz, do ponto de vista evolutivo, dos problemas essenciais com que os organismos se confrontam, sem que isso implique processos computacionais conscientes. Deste modo, no que diz respeito às estratégias actuais da escolha feminina num contexto de longo prazo, e seguindo Buss (1999), os problemas adaptativos teoricamente previstos são, essencialmente, seleccionar um parceiro habili- 
tado e disposto a um investimento continuado na família, capaz de oferecer protecção física e com capacidade para ser bom pai, mostrando-se também um parceiro compatível. A estes problemas corresponderão determinadas preferências adaptativas que a psicologia evolutiva procura testar, através das ideias e dos comportamentos que as traduzem.

Estudos levados a cabo em trinta e sete culturas diferentes através do mundo mostraram que, apesar de algumas variações culturais, as mulheres escolhem preferencialmente parceiros com recursos elevados, homens mais velhos e ambiciosos (Buss, 1989), o que é interpretado como um índice preditivo de potenciais ganhos no futuro. Preferem também homens estáveis e dignos de confiança, capazes de assumir compromissos para com elas e os seus filhos (Buss, Abbott, Angleitner, Asherian, \& Biaggio, 1990); homens mais altos, fortes e saudáveis (Barber, 1995) o que poderia ser indiciado por uma maior simetria da face e do corpo (Gangestad \& Thornhill, 1997); e homens com capacidade para serem bons pais. As mulheres parecem considerar mais atraente um homem fotografado a interagir positivamente com um bebé do que se ele estiver só ou apenas junto de uma criança, enquanto tais diferenças não interferem na opinião dos homens sobre o quão atraente é uma mulher (La Cerra, 1994). A hipótese de que elas valorizariam sobretudo aptidões domésticas, entre as quais se incluiriam os cuidados pelas crianças, não se confirma, na medida em que preferem imagens de um homem inactivo às do mesmo homem aspirando a casa.

Algumas destas preferências serão previsivelmente ajustadas aos contextos particulares de vida das mulheres. No entanto, a hipótese de que a preferência por um parceiro com recursos está relacionada com a falta deles por parte da mulher, ou com falta de poder suficiente para os controlar, não foi confirmada: as mulheres com recursos e estatuto elevado mantêm a preferência ou são ainda mais selectivas (Buss \& Barnes, 1986; Buss, 1989).

No que diz respeito às escolhas masculinas, e sempre num contexto de longo prazo, estas serão guiadas por dois problemas adaptativos diferentes: a necessidade de seleccionar uma parceira com um bom potencial reprodutivo e o problema da incerteza da paternidade (Buss, 1999). É no contexto do primeiro que surge a questão da atractividade ou da beleza feminina: as características femininas preferidas pelos homens seriam interpretadas como sinais de fertilidade potencial, uma vez que a ovulação invisível das mulheres e a sua acessibilidade sexual não limitada a um período de estro evidente dificulta a determinação da sua capacidade reprodutiva imediata. Assim sendo, a juventude e a saúde ou, mais exactamente, os seus supostos sinais - a pele lisa e clara (em relação com o padrão de pigmentação local), a relação entre as medidas da cintura e da anca - são critérios indicativos da capacidade reprodutiva feminina e dão lugar a comportamentos largamente espalhados pelas diversas culturas humanas. Segundo Buss (2008) uma e outra 
característica variam no período ovulatório, em relação com a maior vascularização da pele para a primeira, ou os níveis de estrogénio em circulação para a segunda. Haveria então a possibilidade de existir um mecanismo inconsciente de reconhecimento, pelos homens, da ovulação feminina. Nas sociedades estudadas por Buss et al. (1990), e com excepção dos adolescentes que tendem a preferir mulheres um pouco mais velhas, os homens tendem a escolher mulheres, em média, dois anos e meio mais novas do que eles e tendem a preferir mulheres mais novas à medida que vão envelhecendo. O problema da paternidade incerta confere ao casamento um valor claramente adaptativo, tendo em conta as promessas de estabilidade e de fidelidade sexual entre parceiros que, com ele, geralmente se assumem - mesmo no contexto da variabilidade das formas culturais que pode apresentar. A paternidade incerta dá também sentido à valorização que em certas culturas, sobretudo patriarcais, se confere à virgindade das mulheres (Buss, 1999).

Temos, portanto, entre homens e mulheres, problemas adaptativos diferentes e estratégias comportamentais adaptativas também diferentes que, aliás, não se limitam a questões de atracção, escolha ou capacidade de reter o parceiro. Haverá diferenças comportamentais em praticamente todos os aspectos da vida em conjunto que, a despeito da sua complementaridade, levam frequentemente à existência de conflitos entre os dois sexos. Estes surgem quando o desenrolar da estratégia comportamental de um impede que o outro desenvolva livremente a sua própria estratégia. A teoria da interferência estratégica (Buss, 1999), diferente da interferência própria à luta pelos mesmos recursos entre os indivíduos do mesmo sexo, mostraria por exemplo que as emoções geralmente associadas ao assédio sexual (zanga ou depressão por exemplo) seriam soluções evolutivas que apresentariam a função de alertar para estas interferências. Canalizando a atenção para elas, marcam os acontecimentos e potenciam a sua memorização, desencadeando as acções potencialmente resolutivas do conflito. $\mathrm{O}$ mesmo se aplica às diferenças no ciúme: enquanto o ciúme masculino aparece como centrado no perigo da infidelidade sexual - com raízes evolutivas e históricas no problema da incerteza da paternidade - o ciúme feminino parece relacionar-se mais com a infidelidade emocional que põe em perigo o investimento e o compromisso a longo prazo do parceiro (Buss et al., 1992).

Isto não significa, no entanto, que o conflito seja em si mesmo adaptativo; é antes uma consequência das diferenças e, sempre segundo Buss, a sua existência não contradiz a principal assunção teórica e evidência empírica de que a competição é, primariamente, uma questão entre os indivíduos do mesmo sexo. As observações dos comportamentos animais, em que assenta a teoria da selecção sexual, mostraram que a competição é maioritariamente intrassexual e, no caso dos mamíferos, sobretudo entre machos poligínicos para terem acesso às fêmeas. Deste modo, inúmeras ocasiões serão ocasiões 
privilegiadas para a ocorrência de conflito, desde as diferenças na interpretação de sinais de disponibilidade sexual até às diferenças na avaliação da agressividade nas tácticas usadas. Nada disto impede, no entanto, que homens e mulheres também possam competir por recursos, nomeadamente recursos materiais ou de poder. Com efeito, embora as diversas sociedades se diferenciem na questão da desigualdade entre os sexos, parece ser um dado incontornável que ela frequentemente existe. A psicologia evolutiva considera a hipótese, derivada da teoria da selecção sexual, de que as raízes do poder masculino sobre as mulheres podem ser encontradas na co-evolução da tendência feminina a preferir homens com recursos por um lado e, por outro, na tendência a adquirir recursos como factor essencial da competição entre homens, na luta pelas mulheres (Buss, 1999). Sem negar que outros factores possam também existir (e.g. preferência pela aparência, inteligência, industriosidade), o quadro teórico desta perspectiva sugere que este tipo de relação entre sexos deriva das pressões que a selectividade da escolha de um dos sexos impõe (impôs ao longo da história evolutiva) sobre os indivíduos do sexo oposto. Estabelecem-se assim as "dimensões críticas" (Buss, 1999) em que estes vão competir pelo acesso aos indivíduos do outro sexo. Acentua-se novamente que a competição é, prioritariamente, uma competição entre membros do mesmo sexo.

As diferenças comportamentais entre indivíduos, embora menos exploradas por esta metateoria, poderiam ser explicadas por vários factores: experiências mais ou menos precoces com o ambiente que canalizariam o desenvolvimento pessoal para estratégias adaptativas diferentes, diversos ambientes frequentados na idade adulta que activariam mecanismos particulares de adaptação, ocupação de nichos de competitividade diferenciada. Segundo a psicologia evolutiva, cada pessoa nasceria equipada com um reportório de estratégias potenciais típicas da nossa espécie que o ambiente seleccionaria "fechando-as" em algumas só (Buss, 1999): é o caso da ausência do pai durante os primeiros cinco a sete anos de vida, que determina expectativas sobre recursos e laços entre parceiros pouco seguros, sendo capaz de influenciar a futura estratégia sexual do indivíduo. Neste caso, a maturação e iniciação sexual seria precoce, a mudança de parceiro, como estratégia propícia a um grande número de filhos relativamente pouco investidos, seria frequente. A ausência ou presença do pai é a informação específica que o mecanismo psicológico aqui em causa toma como relevante sendo que as particularidades de um indivíduo implicam a existência de uma grande variedade de traços mais ou menos relacionados, desde os fisiológicos (aqui a precocidade da menarca) aos modelos psicológicos do mundo social ("as pessoas não são dignas de confiança"), aos comportamentos (de risco, por exemplo; Belsky, Steinberg, \& Draper, 1991). De qualquer modo, a flexibilidade de tais mecanismos é sempre uma característica maior, permitindo 
combinações adaptativas e diferenciadas ao longo do tempo de vida dos indivíduos.

Outro fundamento para as variações comportamentais é a "selecção dependente da frequência" (Buss, 1999). Com efeito, as adaptações tornam-se típicas de uma espécie porque as variantes com mais sucesso tendem a substituir as de menos sucesso; mas quando uma das variantes se torna rara, o seu sucesso aumenta levando a que, a mais longo prazo, se instale um novo equilíbrio populacional das variantes. É este tipo de selecção que, por exemplo, explica o equilíbrio entre o número de indivíduos dos dois sexos.

Sem nos ocuparmos aqui de outras sofisticações da teoria como, por exemplo, a que procura explicar a existência de psicopatias e as indicações que tem vindo a fornecer para a psicologia clínica (Lencastre, 2011), resta acentuar que a psicologia evolutiva se apresenta como uma teoria capaz de ultrapassar a dicotomia natureza-cultura. De facto, longe de negar a importância e efeitos da cultura no comportamento e pensamento humanos, a psicologia evolutiva acentua o facto de ela ser produto da mente humana adaptada. Tooby e Cosmides (1992) criticam a perspectiva culturalista acusando-a de usar como explicação (a cultura) o que deve ser explicado (as diferenças culturais). Sugerem assim diferenciar conceptualmente três níveis de análise: metacultura, cultura evocada (evoked culture) e cultura epidemiológica. A primeira refere-se ao facto de que toda a cultura, na medida em que é criada por uma mente produto da evolução, depende do património genético e das suas consequências comportamentais e sociais. As culturas devem, de algum modo, contemplar os grandes problemas comuns a todos os humanos, nomeadamente os da sobrevivência e da reprodução. Com o conceito de cultura evocada pretende-se referir a forma como ambientes físicos e sociais particulares levam a que os diferentes grupos lidem adaptativamente, de forma diferenciada, com esses problemas. É o caso das diversas formas de partilha de alimento, por exemplo, que dependem em grande medida da avaliação da variação futura dos recursos no ambiente. A epidemiologia refere-se às formas como a mente adaptada cria cultura e interage com ela: por que é que as culturas existem, como se faz a aprendizagem e a inovação, qual o papel da linguagem e do simbolismo e, mais particularmente, como e por que razão certas ideias são recriadas na mente de outros indivíduos, para além do que primeiro as concebeu.

A questão da transmissão das representações mentais e os modos como determinadas ideias se espalham mais facilmente do que outras foi também equacionada por Dawkins (1976) com o conceito de meme ${ }^{10}$. Este

10 Trata-se de um termo que pretende evocar explicitamente o de gene e que se refere à sua característica principal de imitação; é portanto uma abreviação de "mimeme" (Dawkins, 2006). 
corresponderia à unidade de informação ou de cultura: tal como para o gene, o que aqui está em causa é a sobrevivência diferencial de entidades culturais (ideias por exemplo) que se replicam e ganham preeminência em determinado ambiente. A sua capacidade de "contágio" depende da sua relevância adaptativa, da facilidade com que são memorizados, da forma como se articulam com outros memes e da forma como dão conta do ambiente.

\section{Conclusão}

Vimos como a etologia humana, a sociobiologia e a psicologia evolutiva, segundo alguns dos seus autores, procuram dar conta das diferenças entre homens e mulheres. A etologia, centrando-se na descrição dos comportamentos observados e procurando invariantes através de estudos comparativos, para tentar compreender o que podem ser os comportamentos diferenciais próprios à espécie e a sua possível história evolutiva. A sociobiologia, procurando analisar os comportamentos sociais com base na assunção teórica de que os organismos procuram maximizar a sua vantagem inclusiva, centrando-se portanto nas consequências comportamentais da transmissão genética diferencial. A psicologia evolutiva, concebendo a "mente adaptada" como um conjunto de dispositivos de tratamento de informação modelados pelo "ambiente de adaptação evolutiva", isto é, na sua maior parte pelas condições de vida dos grupos de recolectores-caçadores humanos. Muitas das críticas às perspectivas biológicas sobre o comportamento humano partem da ideia de que estas identificariam o biológico com o inato, interpretado numa perspectiva determinista como um dado universal e fixo, determinante mas não determinado pela acção humana. No entanto, o conceito major de adaptação implica a ideia de interacção recíproca entre o geneticamente programado e o ambiente, incluindo o ambiente sócio-cultural, ambos continuamente reformulados pela acção humana. A construção cultural de nicho humano é disso um exemplo (Laland, Odling-Smee, \& Feldman, 2000). Na moderna biologia do comportamento, se a cultura é constrangida pela natureza, esta é também produto da cultura - recorde-se de novo, e como exemplo paradigmático, o caso da selecção do gene que codifica para a tolerância à lactose devido à mudança de hábitos alimentares (ver nota 5), ou o caso da presença ou ausência do pai para a idade da maturação sexual no estudo mencionado acima (Belsky et al., 1991). De facto, neste texto não foram considerados algumas propostas mais recentes da genética evolutiva (Cochran \& Harpending, 2009) ou das interacções entre biologia e cultura que nos falam de biologias locais (Lock \& Kaufert, 2001) ou de biologias culturais (Kirnmayer, 2006), isto é, de formas genéticas e epigenéticas de selecção e de desenvolvimento localizados que colocam em questão a universalidade 
dos padrões biológicos humanos a favor de uma mais complexa diversificação evolutiva das morfologias e dos comportamentos.

O presente artigo pretendeu apresentar aos leitores de psicologia três perspectivas evolutivas que ensaiam explicações biológicas para as diferenças constatadas entre os sexos em diversas culturas. Observa-se, no entanto, que a complexidade das estruturas sócio-culturais, nomeadamente da cultura pós-industrial contemporânea onde a discussão sobre o género tem particularmente lugar, não é suficientemente considerada nestes textos. Com efeito, questões como a baixa de natalidade nos países ocidentais, as dinâmicas psicossociais das preferências individuais, as próprias discussões e políticas de género enquanto factores de diversificação das possibilidades sociais, são pouco tomadas em conta por estas perspectivas, o que aponta, particularmente na sociobiologia e na psicologia evolutiva, para uma potencial conflação entre as "causas últimas" e os "factores próximos de motivação". De facto, as causas últimas, como a reprodução individual, apresentam-se através de motivações comportamentais próximas, como o desejo de contacto sexual. Este último não precisa de ser consciente da sua causa evolutiva para se manifestar; deste modo, podemos ter comportamentos motivados sexualmente sem o serem reprodutivamente, o que de facto observamos nos animais, incluindo os humanos. Em termos comportamentais e mentais, são estes mecanismos motivacionais próximos que estão activos; a antropologia mostra por exemplo que há povos que não estabelecem ligação entre relação sexual e reprodução, como foi notado por Malinowski para os povos das ilhas Trobriand (Malinowski \& Ellis, 1929).

Assim, entre os problemas passados e actuais de sobrevivência e de reprodução que homens e mulheres necessariamente enfrentam e os comportamentos sociais observados, inúmeros factores cognitivos, sociais e culturais intervêm que solicitam explicações mais finas do que a suposição de mecanismos psicológicos evoluídos directamente derivados das pressões selectivas. Segundo Panksepp e Panksepp (2000) um dos problemas da psicologia evolutiva consiste na aceitação massiva de adaptações cortico-cognitivas discretas (os módulos) como se fossem características de Homo, quando elas reflectem as adaptações emocionais e motivacionais mais antigas, encontradas pela etologia no grupo dos mamíferos. Ao invés de procurar o substrato cortico-cognitivo para esses supostos módulos, a psicologia evolutiva deveria interessar-se pelas interacções entre as zonas mais antigas do cérebro de mamífero com as zonas corticais mais evoluídas, onde se dão os processos perceptivos, associativos e cognitivo-linguísticos específicos dos humanos. Daria deste modo razão aos factores cognitivos, sociais e culturais que se articulam com os factores biológicos.

Outro tipo de questões estão também por resolver nestas disciplinas: desde questões que dizem respeito à potencial ideologia naturalista e ao seu 
uso social e político (e.g. potencial justificação das diferenças sociais, racismo, sexismo), à linguagem utilizada que apresenta por vezes conotações finalistas de que é difícil abstrair: é o caso da expressão "estratégias evolutivas estáveis" ou de "altruísmo", ainda que este último seja definido estatisticamente como comportamento observado e não como motivação subjectiva. Esta e outras questões abrem, portanto, interrogações sobre a linguagem e o seu uso, nomeadamente quando se passa do contexto específico à disciplina para outros contextos disciplinares, mais ainda, quando se passa da disciplina para a divulgação a um público não especializado.

De facto, as disciplinas que aqui abordamos ocupam-se de comportamentos actualmente observados, tentando reconstruir as possíveis pressões selectivas que os modelaram. Trata-se portanto de uma reconstrução "histórica" e não de uma reificação biológica comprometendo a mudança evolutiva, presente ou futura (o que, aliás, iria contra a dinâmica evolutiva aqui apresentada). Todas estas disciplinas apontam para a importância da intervenção consciente humana nos contextos adaptativos de vida, no sentido em que são estes que, ultimamente, condicionam a selecção e expressão dos comportamentos sociais. Não é a biologia que apresenta uma perspectiva valorativa ou finalista, pressupondo um qualquer objectivo a seguir: o facto de determinado comportamento seleccionado favorecer a descendência futura de um dado organismo, e portanto a persistência desse comportamento na população futura, não significa que esta seja o motivo de tal comportamento - "a evolução é cega em relação ao futuro", diz Dawkins (2006). Mas os humanos podem definir objectivos evolutivos e históricos desejáveis e, nesse sentido, criarem as condições para que esses objectivos se realizem. O conhecimento das condições biológicas dos comportamentos humanos, na sua variedade, é um elemento central para a definição e prossecução desses objectivos.

\section{Referências}

Barber, N. (1995). The evolutionary psychology of physical attractiveness: Sexual selection and human morphology. Ethology and Sociobiology, 395-424.

Barkow, J., Cosmides, L., \& Tooby, J. (Eds.). (1992). The adapted mind: Evolutionary psychology and the generation of culture. Nova Iorque, Oxford: Oxford University Press.

Belsky, J. Steinberg, L., \& Draper, P. (1991). Childhood experience, interpersonal development, and reproductive strategy: An evolutionary theory of socialization. Child Development, 62, 647-670.

Block, J. H. (1976). Database conclusions about sex differences. Contemporary. Psychology, 21, 527-522. 
Buss, D. M. (1989). Sex differences in human mate preferences: Evolutionary hypotheses testing in 37 cultures. Behavioral and Brain Sciences, 12,1-49.

Buss, D. M. (1999). Evolutionary Psychology. The new science of the mind. Needham Heights, MA: Allyn e Bacon.

Buss, D. M. (2008). Evolutionary Psychology. The new science of the mind. USA: Pearson.

Buss, D. M., \& Barnes, M. (1986). Preferences in human mate selection. Journal of Personality and Social Psychology, 50, 559-570.

Buss, D. M., Abbott, M., Angleitner, A., Asherian, A., Biaggio, A., Blanco-Villasenor, A., Bruchon-Schweitzer, M., Ch'U H-Y, Czapinski, J., Deraad, B., Ekehammar, B., et al. (1990). International preferences in selecting mates: A study of 37 cultures. Journal of Cross-Cultural Psychology, 21, 5-47.

Buss, D. M., Larsen, R., Westen, D., \& Semmelroth, J. (1992). Sex differences in jealousy: evolution, physiology, and psychology. Psychological Review, 3, 251-255.

Buss, D. M., \& Schmidt, D. (1993). Sexual strategies theory: An evolutionary perspective on human mating. Psychological Review, 100, 204-232.

Cavalli-Sforza, L. (1981). Human evolution and nutrition. In N. Kretschmer \& D. Walcher (Eds.). Food, Nutrition and Evolution. Nova Iorque: Masson Publ. Inc.

Darwin, C. (1871). The descent of man and selection in relation to sex. Londres: Murray.

Dawkins, R. (2006). The Selfish Gene. Oxford, Nova Iorque: Oxford University Press. (Original publicado em 1976).

Degenhardt, A., \& Trautner, H. (1979). Geschlechtstypisches Verhalten. Mann und Frau in psychologischer Sicht [Comportamento típico dos sexos. Homem e mulher do ponto de vista psicológico]. München: C.H.Beck.

Dörner, G. (1981). Sexual differentiation of the brain. Vitamins \& Hormones, 38, 325-381.

Durden-Smith, J., \& Desimone, D. (1983). Sex and the Brain. Nova Iorque: Arbor House.

Eibl-Eibesfeldt, I. (2010). Human Ethology. New Brunswick (USA) e Londres (UK): AldineTransaction (Original publicado em 1989).

Fagot, B. (1978). The influence of sex child on parental reactions to toddler children. Child Development, 49, 459-465.

Feldman, J., Brody, N., \& Miller, S. (1980). Sex differences in non-ellicited neonatal behaviors. Merril-Palmer Quarterly, 26, 63-73.

Fisher, H. E. (1994). Anatomia do amor: a história natural da monogamia, do adultério e do divórcio. Lisboa: Publicações Dom Quixote.

Gangestad, S. \& Thornhill, R. (1997). Human sexual selection and developmental stability. In J. Simpson, \& D. Kenrick (Eds.), Evolutionary Social Psychology, (pp. 169-195). Mahwah, NJ: Erlbaum.

Gladue, B., Green, R., \& Hellman, R. (1984). Neuroendocrine response to estrogen and sexual orientation. Science, 225, 1496-1499. 
Goldberg, S., \& Lewis, M. (1969). Play behavior in the year-old infant: Early sex differences. Child Development, 40, 21-31.

Grant, V. (1998). Maternal personality, evolution and the sex ratio: do mothers control the sex of the infant?. Londres e Nova Iorque: Routledge.

Grusec, J., \& Brinker, D. (1972). Reinforcement for imitation as social learning determinant with implications for sex-role development. Journal of Personality and Social Psychology, 21, 149-158.

Hamilton, W. D.(1964). The genetical evolution of social behavior. Journal of Theoretical Biology, 7, 1-52.

Heinroth, O. (1910). Beiträge zur Biologie, insbesondere Psychologie und Ethologie der Anatiden.Verhalten 5.Internationaler Ornithologischer Kongess [Contribuições para a biologia, particularmente a psicologia e a etologia dos anatídeos. Comportamento 5. Congresso Ornitológico Internacional]. Berlin.

Hold, B. (1974). Rangordnungsverhalten bei Vorschulkindern [Comportamento de ordenação do estatuto em crianças pré-escolares]. Homo, 25, 252-267.

Hold, B. (1976). Attention structure and rank specific behaviour in pre-school children. In M. 1. Chance, The Social Structure of Attention (pp. 177-201). Londres: Wilwy.

Imperato-McGinley, J., Peterson, R., Gautier, T., \& Sturla, E. (1979). Androgens and the evolution of the male gender-identity among male pseudohermaphrodites with 5areductase deficiency. New England Journal of.Medicine, 300, 1233-1237.

Jessen, E. (1981). Untersuchungen zur Geschlechtererkennung - Die Zuordnung einfacher geometrischer Formen zu Mann und Frau in verschiedenen Altersstufen und Kulturen. Dissertation [Estudos para o reconhecimento de género - a atribuição de formas geométricas simples em homens e mulheres de diferentes faixas etárias e culturas. Dissertação]. München: Ludwig-Maximilian-Universität.

Kallman, F. (1952). A comparative twin study on the genetic aspects of male homossexuality. Journal of Nervous and Mental Disease, 115, 283-298.

Keller, H. (1979). Die Entstehung von Geschlechtsunterschieden im ersten Lebensjahr [O surgimento de diferenças de género no primeiro ano de vida]. In A. T. Degenhardt (Ed.), Geschlechtstypisches Verhalten [Comportamento típico do sexos] (pp. 122-144). München: C. H. Beck.

Keverne, E., Levy, F., Poindron, P., \& Linssay, D. (1983). Vaginal stimulation: an important determinant of maternal bonding in sheep. Science, 219, 81-83.

Kirmayer, L. J.(2006). Beyond the new "cross-cultural psychiatry". Cultural biology, discursive psychology and the ironies of globalization. Transcultural Psychiatry, 43, 126-144.

Klopfer, P. (1971). Mother love: What turns it on? American Science, 59, 404-407.

Kohlberg, L. A. (1966). A cognitive-developmental analysis of children's sex-role concepts and attitudes. In E. Maccoby, (Ed.), The Developmental of sex differences (pp. 82-173). Stanford: Stanford University Press.

Kokko, H., Brooks, R., Jennions, M., \& Morley, J. (2003). The evolution of mate choice and mating biases. Acedido em 29 de Junho de 2011, The Royal Soci- 
ety review on line: http://rspb.royalsocietypublishing.org/content/27071515/ 653.abstract

Krafft-Ebing, R. (1924). Psychopathia sexualis (17th ed.). Stuttgart.

La Cerra, M. (1994). Tactics as units of analysis in personality psychology: An illustration using tactics of hierarchy negotiation. Santa Barbara: Unpublished doctoral dissertation, Department of Psychology, University of California.

Laland, K. N., Odling-Smee, F. J., \& Feldman, M.W. (2000). Niche construction, biological evolution and cultural change. Behavioral Brain Sciences, 23, 131-175 .

Lamb, M. (1977a). Father-infant and mother-infant interaction in the first year of life. Child Development, 48, 167-181.

Lamb, M. (1977b). The relationships between mothers, fathers, infants and siblings in the first two years of life. Paper presented at the Biennial Conference of the International Society for the Study of Behavioral Development. Pavia: Italian.

Lee, R. B., \& DeVore, I. (1968). Man the Hunter. Chicago: Aldine.

Lencastre, M. P. A. N. (2011). Etologia e psicologia evolutiva: contribuições para a psicologia clínica, Psychologica, 52, 149-192.

Leonhard, K. (1966). Über die Entstehung einer Form von Homosexualität durch ein Prägungserlebnis [Sobre a emergência de uma forma de homossexualidade através de uma experiência de cunhagem]. Leopoldina, 12, 44-152.

Levy, J. (1972). Lateral specialization of the human brain: Behavioral manifestations and possible evolutionary basis. In J. A. Kinger, (Ed.) The Biology of Behavior. Corvallis, OR: Oregon State University Press.

Ley, R., \& Koepke, J. (1982). Attachment behavior outdoors: Naturalistic observations of sex and age differences in the separation behavior of young children. Infant Behavior Development, 5, 195-201.

Leyhausen, P. (1983). Kleindung: Schutzhülle, Selbstdarstellung, Ausdrucksmittel. In B. Sitta,(Ed.). Menschliches Verhalten, sein biologischen un kulturellen Komponenten, Untersucht an den Phänomenen Arbeitsteilung und Kleidung [Roupa: Capa protectora, auto-apresentação, meio de expressão. In B. Sitta, (Ed.). O comportamento humano, seus componentes biológicos e culturais, investigação dos fenómenos da divisão do trabalho e da roupa]. Freiburg/Schweiz: Universitätsverlag.

Lock, M., \& Kaufert, P. (2001). Menopause, local biologies and cultures of aging. American Journal of Human Biology, 13, 494-504.

Lorenz, K. (1935). Der Kumpan in der Umwelt des Vogels [O companheiro no ambiente das aves]. J. Ornithologie, 83, 137-413.

Lorenz, K. (1973). Die Rückseite des Spiegels. Versuch einer Naturgeschichte menschlichen Erkennens [O inverso do espelho. Ensaio sobre uma história natural do conhecimento humano]. München: Piper.

MacCoby, E., \& Jacklin, C. (1974). The psychology of sex differences. Stanford CA: Stanford University Press.

MacCoby, J. (1980). Sex differences in aggression: A rejoinder and reprise. Child Development, 51, 964-980. 
Malinowski, B., \& Ellis, H. (1929). The sexual life of savages in North-Western Melanesia. An ethnographic account of courtship, marriage, and family life among the natives of the Trobriand Islands, British New Guinea. New York: Harcourt.

Maynard-Smith, J., \& Price, G. (1973). The logic of animal conflicts. Nature, 246, 15-18.

Mazur, A., \& Lamb, T. A. (1980). Testosterone, status, and mood in human males. Hormones and Behavior, 14, 235-246.

Money, J., \& Ehrhardt, A. (1972). Man and woman, boy and girl: The differentiation and dimorphism of gender identity from conception to maturity. Baltimore: John Hopkins University Press.

Müsch, H. (1976). Exhibitionismus, Phalluskult und Genitalpräsentieren [Exibicionismo, culto do falo e apresentação genital]. Sexualmedizin. 5, 358-363.

Ochran, G., \& Harpending, H. (2009). The 10.000 year explosion: How civilization accelerated human evolution. Nova Iorque: Basic Books.

Panksepp, J., \& Panksepp, B. (2000). The seven sins of evolutionary psychology. Evolution and Cognition, 6-2, 108-131.

Phillips, S., King, S., \& Dubois, L. (1978). Spontaneous activities of female versus male newborn. Child Development, 49, 590-597.

Popper, K. (2010). Notes of a realist on the body-mind problem. In K. Popper, All Life is Problem Solving (pp. 23-35). Nova Iorque: Routledge. (Original publicado em 1999).

Rubin, R., Reinich, J., \& Haskett, R. (1981). Postnatal gonodal steroid effects on human behavior. Science, 211, 1318-1324.

Sbrzesny, H. (1976). Die Spiele der !Ko-Buschleute. Monographien zur Humanethologie 2 [Os jogos do povo Ko-bosquímano. Monografia para a etologia humana 2]. München: Piper.

Shigetomi, C., Hartmann, D., \& Gelfand, D. (1981). Sex differences in children's altruistic behavior and reputations for helpfulness. Developmental Psychology, $17,434-437$.

Shostak, M. (1981). Nisa, life and words of a !Kung woman. Cambridge, MA: Harvard University Press.

Silverman, I., \& Phillips, K. (1998). The evolutionary psychology of spatial sex differences. In K. D. Crawford, \& D.L.Krebs, (Eds), Handbook of evolutionary psychology (pp. 595-612). Mahwah, NJ: Erlbaum.

Slaby, R., \& Frey, K. (1975). Development of gender constancy and selective attention to same-sex models. Child Development, 46, 849-856.

Spiro, M. E. (1979). Gender and Culture: Kibbutz Women Revisited. Durham, North Carolina: Duke University Press.

Symons, D. (1979). The evolution of human sexuality. Nova Iorque: Oxford.

Tauber, M. (1979). Sex differences in parent-child interaction styles during a free-play session. Child Development, 50, 981-988.

Tiger, L., \& Shepher, J. (1975). Women in the kibbutz. Nova Iorque: Harcourt, Brace Jovanovich, Inc. 
Tinbergen, N. (1951). The study of instinct. Nova Iorque: Oxford University Press.

Tooby, J., \& Cosmides, L. (1992). The psychological foundations of culture. In J. Barkow, L.Cosmides, \& J.Tooby, (Eds.) The adapted mind (pp. 19-136). Nova Iorque: Oxford University Press.

Tooby, J., \& De Vore, I. (1987). The reconstruction of hominid behavioral evolution through strategic modeling. In W. G.Kinzey, (Eds.) The evolution of human behavior (pp. 183-237). Nova Iorque: State University of New York Press.

Trautner, H. M. (1979). Psychologische Theorien der Geschlechtsrollen-Entwicklung. In A. Degenhardt, \& H. M. Trautner, (Eds.) Geschlechtstypiches Verhalten [Teorias psicológicas do desenvolvimento do papel de género. In A. Degenhardt, \& H.M. Trautner (Eds.) Comportamento típico do sexo]. (pp. 50-84). München: C.H.Beck.

Trivers, R. (1972). Parental investment and sexual selection. In B. Campbell, Sexual selection and the descent of man: 1871-1971 (pp. 136-179). Chicago: Aldine.

Trivers, R. (1974). Parent-offspring conflict. American Zoologist, 14, 249-264.

Trivers, R., \& Willard, D. (1973). Natural selection of parental ability to vary the sex ratio of offspring. Science, 179, 90-92.

Vieira, A. (2009). A evolução do darwinismo. Lisboa: Fim de Século.

Wilson, E.O. (1975). Sociobiology: The new synthesis. Cambridge: MA: Harvard University Press.

Wilson, E. O. (2004). On human nature. Cambridge, MA; Londres: Harvard University Press (Original publicado em 1978).

Witkin, H., Goodenough, D., \& Karp, S. (1967). Stability of cognitive style from childhood to young adulthood. Journal of Personality and Social Psychology 7, 291-300. 